\title{
Research on the Changed Operating Parameters during Operation MMAT 110-03 and IDK 120-04 Nozzles
}

\author{
Ovidiu MARIAN, Ioan DROCAȘ *, Adrian MOLNAR, Mircea MUNTEAN, Ovidiu RANTA \\ Faculty of Agriculture. University of Agricultural Science and Veterinary Medicine, Cluj - Napoca, \\ Romania \\ *corresponding author, e-mail: drocas_i@yahoo.fr
}

Bulletin UASVM series Agriculture 73(1)/2016

Print ISSN 1843-5246; Electronic ISSN 1843-5386

DOI 10.15835/buasvmcn-agr: 12009

\begin{abstract}
The quality of the phytosanitary treatments and weed control depends on the amount of solution administered uniformly per unit area, coverage and penetration of plant mass, fluid flow rates and droplet size. Most of these indices are fulfilled by nozzles. The most important parts of the sprayer are nozzles. They produce herbicide mixture in small sized droplets that are sent to target surface. This stream of droplets containins particles of different sizes. Measurements were made at the Department of Technical and Soil Sciences, using EP 70 sprayer manufactured by Tehnofavorit Bonțida and data acquisition was realized using the test benchmark TEST 1000 produced by the German firm Herbst.
\end{abstract}

Keywords: nozzle wear, nozzles type, nozzle flow.

\section{INTRODUCTION}

One of the most important work done in the field is the plant treatment. For farmer is important to have a productive culture, as we need to carry herbicides, treatment of diseases and pests.

Adequate and precise pesticide application is necessary due to permanent costs increase of chemical plant protection and requirement for environment pollution decrease, especially of ground water pollution. Large amount of pesticide is dissolved in water prior to their application and used by spraying machines via hydraulic nozzles. Thus they are very important at chemical preparations application in plant protection. Nozzles play an important role at pesticides application: they leak given liquid proportion in a time unit, atomize liquid forming droplets of suitable sizes as well as stream of adequate shape. Changes in the given nozzle functions may affect efficiency of applied chemical preparations.
All these treatments are carried out using machines and equipment for treatments. For a good yield, to save time and money we need more precise setting of this goal is achievable with nozzles quality and strength. First we must consider the coverage, type and flow nozzles. The choice of the right nozzle and corresponding adjustments lead to fulfilled requirements.

\section{MATERIALS AND METHODS}

In order to achieve the experimental tests two different types of nozzles were used, with the same operating parameters (pressure 3 bars). To determine the nozzle wear a portable equipment was used. This equipment worked 24/24, for 1100 hours at IDK nozzle and 296 hours at MMAT nozzle.

In figure 1 is presented the TEST 1000 benchmark equipment and in figure 2 the computer used for the determination of the flow. 
The spraying equipment Ep 70 was installed in a room and it functioned for 1100 hours. It is an electric motor driven equipment and has a membrane and piston pump. In order to achieve the experiment objectives, this equipment was modified to deliver the liquid into a ramp. The ramp was fitted with 4 nozzles (figure 3 ).

During the experiment the installation worked 24 hours a day for more than a month. The liquid used was water in a closed circuit $(70$ 1). The pressure used was 3 bar and kept constant. After the initial measurement, all the other data collecting activities were made every 2 hours.

\section{RESULTS AND DISCUTIONS}

In figures 4 is presented the results for the IDK 120-04 nozzle and in figures 5 for MMAT 12003 nozzle.

Analysing the data recorded for the IDK 12004 nozzle it can be observed that the wear occurs in certain amount of time.

For the left nozzle the correlation coefficient between the usage time and change in nozzle flow is 0,92 . This means a strong correlation between these two factors. The determination coefficient of 0,82 indicates that there are others influences in change of the flow. Several fluctuations were recorded during the experiment due to the EP 70 spraying equipment.

For the central nozzles B and C (figure 4) the results obtained were very similar. The determination coefficient of 0,8816 and 0,8801 indicates that the nozzles were warn equally. That is possible because these two nozzle were placed near the liquid entrance into the ramp.

The right nozzle has registered a 0,89 determination coefficient, slightly higher than the left one. This can occur because of some sediments inside the ramp.

For the MMAT nozzles the results indicate a relation between the usage time and change in nozzle flow.

The determination coefficient ranged from 0,3534 (centre) to 0,749 (right side). As it can be seen the middle nozzles registered lower correlations than the outer placed nozzles. This can be an indicator of uneven wear, although nozzles were from the same lot.

\section{CONCLUSIONS}

Nozzle orifice wear occur when using different substances. The time it takes a nozzle to wear beyond the use limit depends on the materials from which is constructed and the substances used.

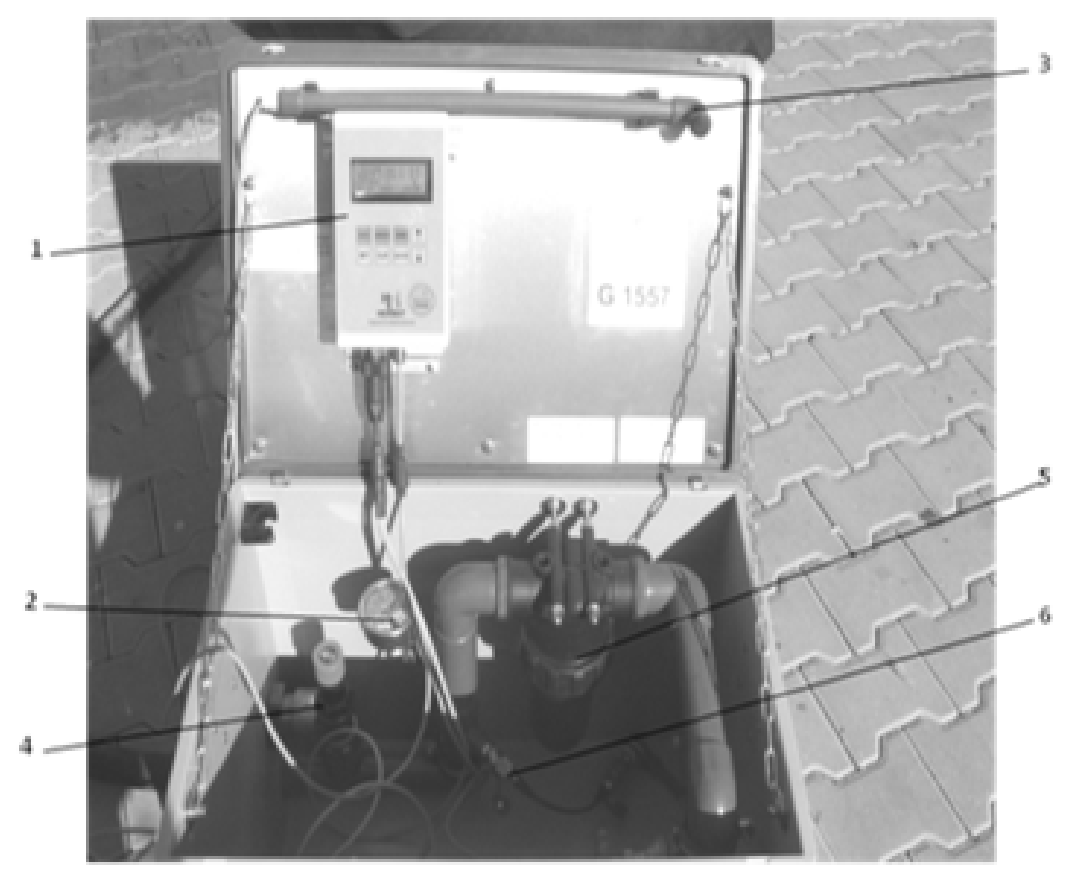

Fig. 1. Herbst equipment

1- computer; 2- manometer; 3-tachometer; 4- safety valve; 5- filter; 6- pressure sensor 


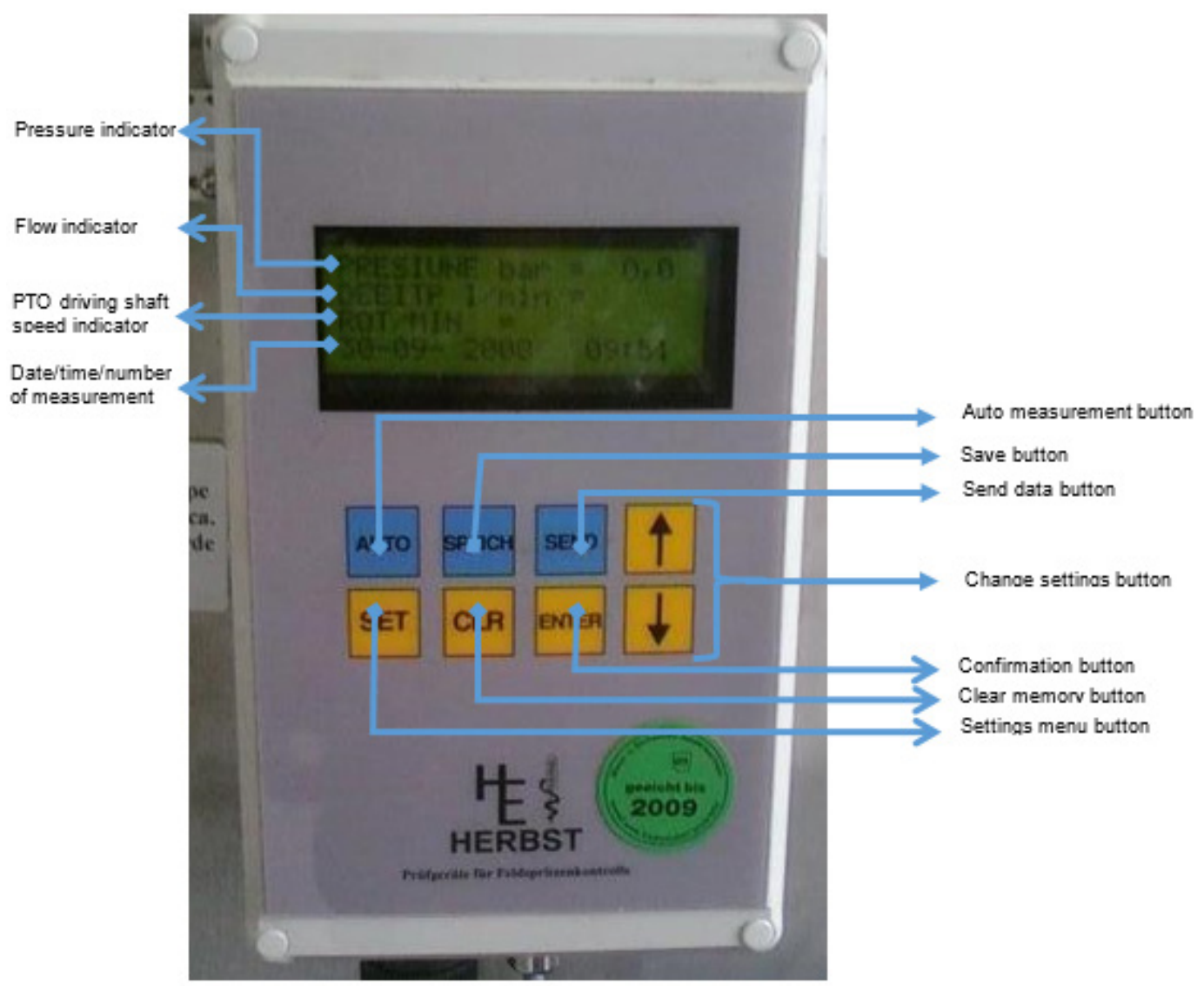

Fig. 2. Herbst computer for the determination of the flow rate.

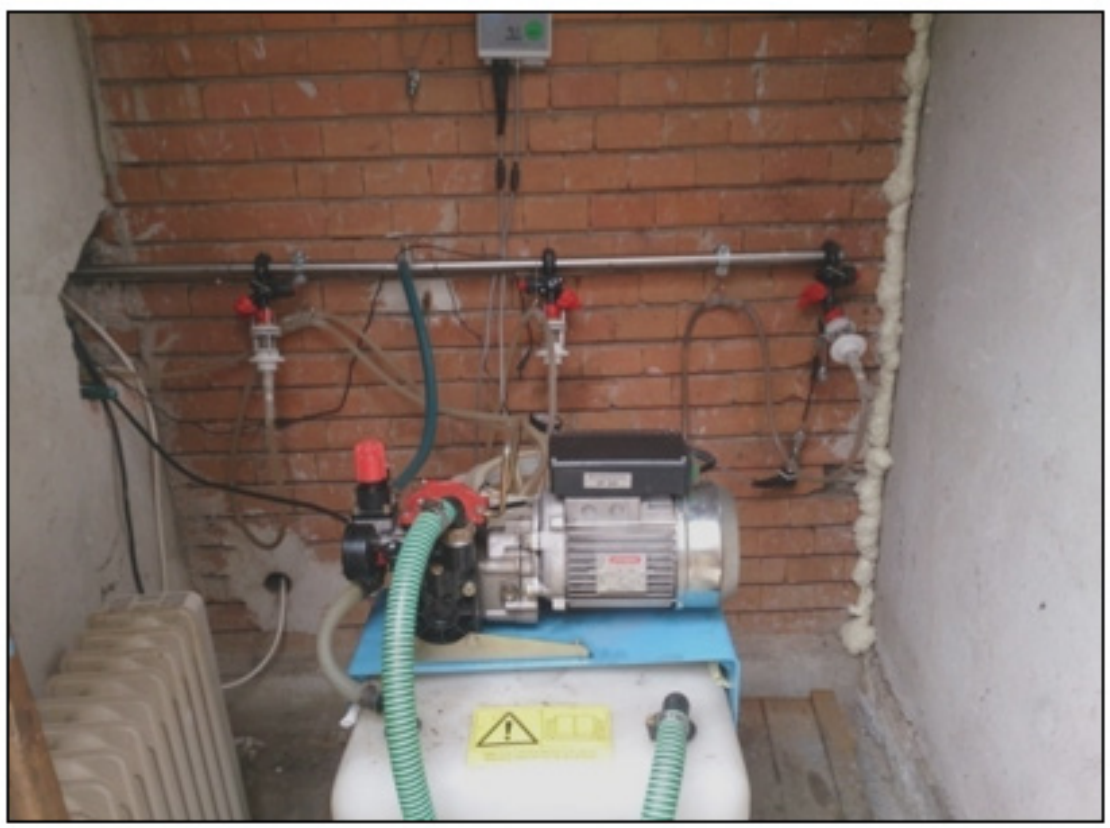

Fig. 3. The Ep 70 equipment 


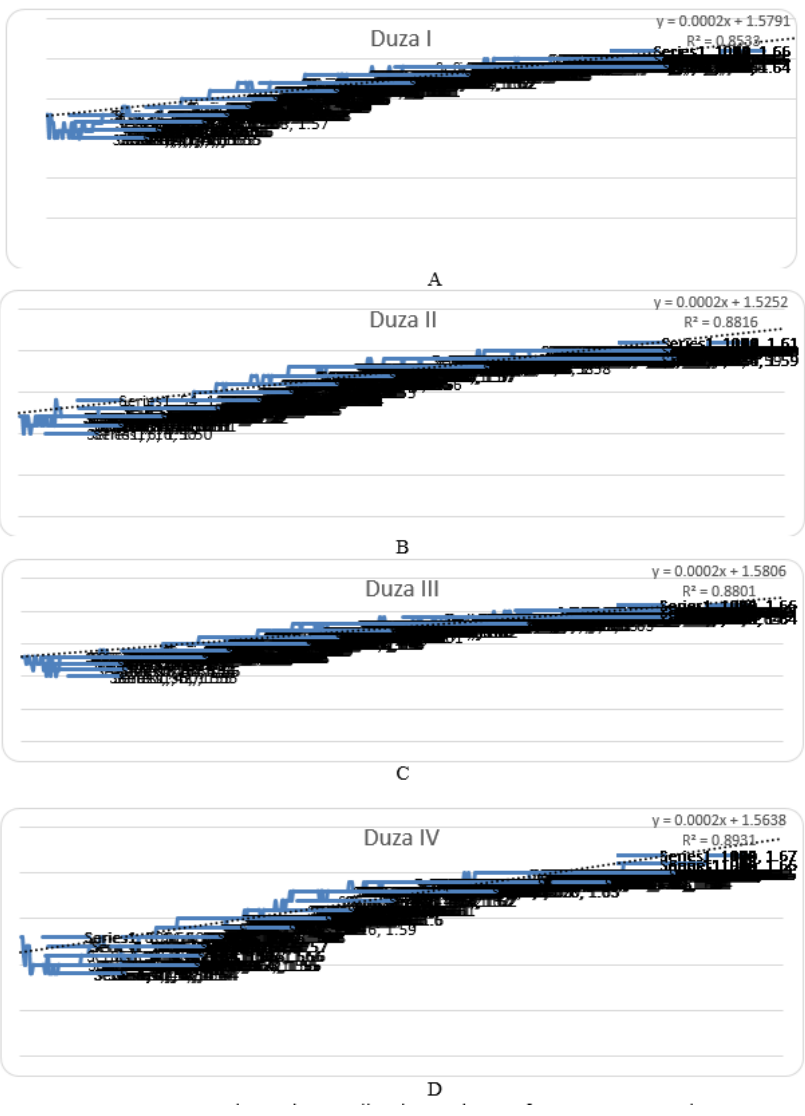

Fig. 4. The results regarding the nozzle wear for IDK 120-04 nozzle

A- left nozzle; B, C - center nozzles; D - right nozzle.

1. Both nozzles IDK and MMAT are made from the same materials class (POM - Polyoxymethylene), but the IDK nozzle functioned more time.

2 . The IDK nozzles reached a difference of $5 \%$ from the nominal flow after 1100 hours of functioning.

3. The MMAT nozzles reached a difference of $5 \%$ from nominal flow after 296 hours.

4. The time in which both nozzles reached the 5 $\%$ difference is different. The MMAT nozzle reached this threshold five time faster than IDK. This fact indicates a higher durability material from which IDK nozzle is made.

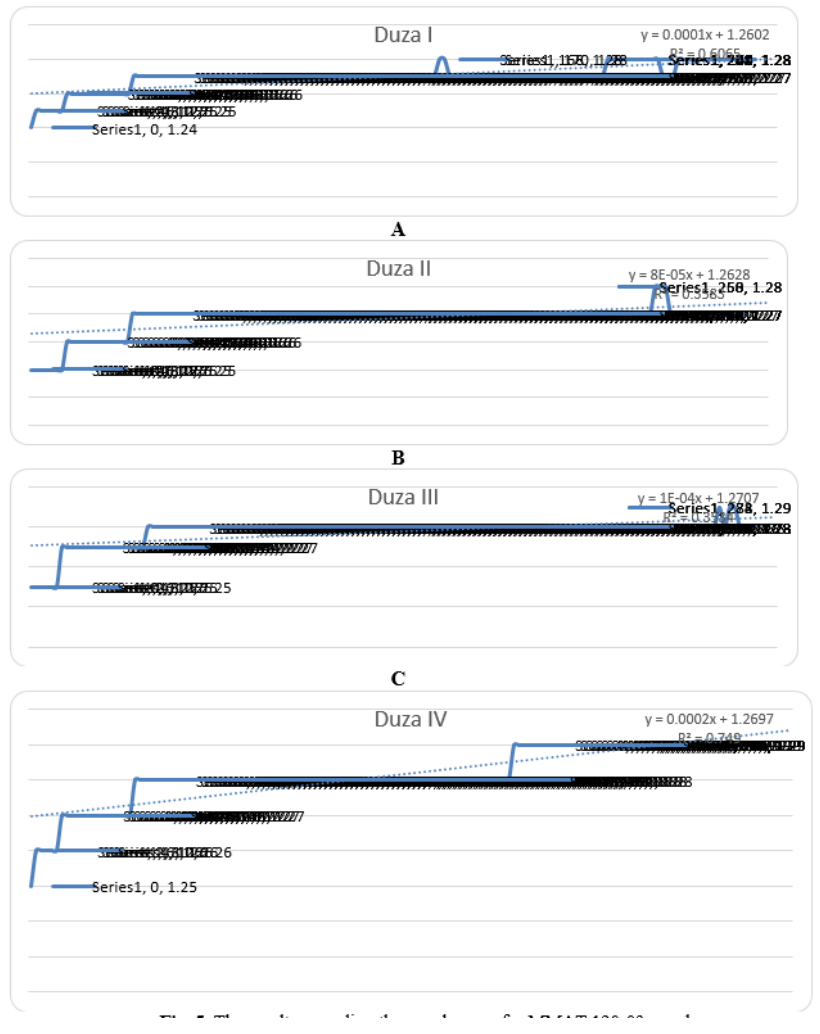

Fig. 5. The results regarding the nozzle wear for MMAT 120-03 nozzle

A- left nozzle; B, C - center nozzles; D - right nozzle.

5. In order to increase the lifespan of nozzles the plastic type should be checked regularly.

\section{REFERENCES}

1. Drocaş, I., V. Sârb, V. Gherman, V. Bărbieru, 2002. The control and diagnose of the spraying machines. În Simpozionul agricultură şi alimentație -perspective la început de mileniu III. Buletinul USAMV, Cluj-Napoca, vol. 57

2. Stahli, W, 2003, Mașini pentru aplicarea tratamentelor fitosanitare și fertilizare foliară în legumicultură, Ed. Agroprint, Timișoara.

3. XXX, ISO 5682-2: 1997, Agricultural machinery and tractors - Equipment for crop protection - Test methods for sprayer nozzles, Geneva. 